\title{
PEMBELAJARAN BISINIS ONLINE BERBASIS ANDROID DALAM MENGEMBANGKAN SENSE ENTREPRENEURSHIP SISWA MENGHADAPI REVOLUSI INDUSTRI 4.0
}

\author{
Moh. Hafidurrahman \\ Institut Agama Islam (IAI) Al-Khairat Pamekasan \\ Hafidzbarizi@gmail.com
}

\begin{abstract}
Online business is a phenomenon, almost comprehensive practice carried out by almost all levels of society, both professional business people and those who have spare time such as housewives, employees, and students. This is a very phenomenal cycle of time that the world of education needs to address wisely. For business people who are professional, they make online business their main job. For students, this might be an opportunity to hone their entrepreneurial spirit. in an effort to reduce the number of jobless or unemployed in the Industrial Revolution 4.0 era.

Indonesia has been predicted to experience a demographic bonus in 2030-2040. Here the authors find two trends that make the author interested, first, there are many people who tend to do shopping online, the second is the tendency of people of selling online. In facing the digital era and preparing students to face the demographic bonus era, education must also morph how to develop students' entrepreneurial spirit. through learning patterns in the classroom, in this paper we focus on learning in the digital era where learning is grouped into three models, namely: the conventional face-to-face model; online models and automation; and the blended learning model. From some of the learning models above, the appropriate learning model to be applied in digitizing education is mainly related to the ability to market goods, so the blended learning model is very appropriate learning. Where this learning model combines web-based online learning (e-learning) and face-to-face learning in the classroom or in the laboratory which is of course androidbased which is owned by the students themselves.
\end{abstract}

Keyword: Bussines online, era revolution 4.0 


\begin{abstract}
Abstrak
Bisnis online adalah sebuah fenomina, sebuah kelataan yang hampir menyeluruh dilakukan oleh hamper seluruh lapisan masyarakat, baik pelaku bisnis yang telah profesional maupun bagi mereka yang memiliki waktu luang seperti ibu rumah tangga, karyawan, mahasiswa dan pelajar sebagai pekerjaan sampingan. Ini adalah siklus waktu yang sangat fenominal yang perlu disikapi dengan bijak oleh dunia pendidikan. Bagi pelaku business yang telah professional, mereka menjadikan bisnis online sebagai pekerjaan utama. Bagi para siswa mungkin ini menjadi momentum mengambil kesempatan untuk mengasah jiwa kewirausahaannya. dalam usaha mengurangi angka jobless atau pengangguran di Era Revolusi Industri 4.0. Ditambah lagi Indonesia telah diprediksi akan mengalami bonus demografi pada tahun 20302040, yaitu penduduk dengan usia produktif lebih banyak dibandingkan dengan penduduk non produktif. Disini penulis menemukan dua kecenderungan yang membuat penulis tertarik, pertama banyak orang kecenderungan belanja online, yang kedua kecenderungan orang menjajakan secara online.Dalam menghadapi era digital plus menyiapkan siswa menghadapi zaman bonus demografi tersebut, maka pendidikan harus juga bermertamorfosis bagaimana mengembangkan jiwa entrepreneurship siswa, tentunya melalui pola pembelajaran di dalam kelas, dalam paper ini kami fokuskan pada pembelajaran di era digital dimana pembelajaran ini dikelompokkan menjadi tiga model yaitu: model konvensional face-to-face; model daring dan otomatisasi; serta model blended learning. Dari beberapa model pembelajaran diatas maka model pembelajaran yang tepat untuk diterapkan dalam digitalisasi pendidikan terutama berkaitan dengan kemampuan memasarkan barang maka model pembelajaran blended learning adalah pembelajaran yang sangat tepat. Dimana model pembelajaran ini memadukan pembelajaran online berbasis web (e-learning) dan pembelajaran face-to-face di kelas atau di laboratorium yang tentunya berbasis android yang dimiliki oleh siswa itu sendiri.
\end{abstract}

Kata Kunci : Bisnis online, Pembelajaran, era revolusi industry 4.0

\title{
Latar belakang
}

Seiring dengan masuknya zaman pada masa revolusi industry 4.0 maka pola pendidikan akan mengalami perubahan. Pendidikan akan menuntut adanya perubahan desain dan pola pembelajaran sesuai dengan zamannya. Apalagai memasuki era revolusi industri 4.0. atau revolusi industri dunia yang ke-empat dimana technologi telah menjadi basic dalam kehidupan manusia (human life). Semuanya menjadi ruang tanpa batas akibat perkembangan teknologi digital 
utamanya internet. Era ini telah mempengaruhi banyak sisi kehidupan manusia baik di bidang ekonomi, politik, kebudayaan, seni, dan bahkan sampai dalam pendidikan.Oleh karnenya era ini lebih identic dengan super computer, artificial intelligence, big data, 5G (five G) dan social media. Mencerdaskan anak bangsa adalah salah satu cita-cita suci negara, hal ini tercantum dalam Pembukaan UUD 1945 alinea ke-4.

Selaras dengan Al-qur'an telah menjelaskan bahwa manusia harus melakukan perubahan dalam surat Ar-ra'du yang artinya: Sesungguhnya Allah tidak akan mengubah keadaan suatu kaum sebelum mereka mengubah keadaan mereka sendiri (QS. Ar-Ra'd:11). Secara tersirat ayat tersebut mengindikasikan perlunya manusia berubah. Barang siapa yang menolak perubahan pasti akan ketinggalan zaman karena perubahan adalah suatu yang mutlak. Perubahan tersebut bisa saja bersifat gradual, ataupun bersifat systematis. Dan globalisasi adalah Salah satu bentuk perubahan yang paling nyata. Interaksi antar individual, antar komunity, hingga antarbangsa terjadi dengan begitu fast dan quick (cepat). Para pakar dalam bidang ilmiyah menjelaskan bahwa perubahan sebagai time dimension (dimensi waktu) . Dunia saling terkoneksi dalam satu masa hanya disekat oleh batas-batas semu atau maya. Dimensi perubahan dalam periode human life ditandai dengan banyak hal, salah satunya adalah industrial revolution change yaitu perubahan revlusi industry di era industry 4.0.

Sejarah revolusi industri dimulai dari industri 1.0, 2.0, 3.0, hingga industri 4.0. Fase industri merupakan real change dari perubahan yang ada. Industri 1.0 ditandai dengan mekanisasi produksi untuk menunjang efektifitas dan efisiensi aktivitas manusia, industri 2.0 dicirikan oleh produksi massal dan standarisasi mutu, industri 3.0 ditandai dengan penyesuaian massal dan fleksibilitas manufaktur berbasis otomasi dan robot. Industri 4.0 selanjutnya hadir menggantikan industri 3.0 yang ditandai dengan cyber fisik dan kolaborasi manufaktur. ${ }^{1}$

Lee et al (2013) menjelaskan, industri 4.0 ditandai dengan peningkatan digitalisasi manufaktur yang didorong oleh empat faktor: 1) peningkatan volume

${ }^{1}$ Irianto, D. (2017). Industry 4.0; The Challenges of Tomorrow. Disampaikan pada Seminar Nasional Teknik Industri, Batu-Malang. 
data, kekuatan komputasi, dan konektivitas; 2) munculnya analisis, kemampuan, dan kecerdasan business; 3) terjadinya bentuk interaksi baru antara manusia dengan mesin; dan 4) perbaikan instruksi transfer digital ke dunia fisik, seperti robotika dan 3D printing. Jadi prinsip dasar industri 4.0 adalah penggabungan mesin, alur kerja, dan system, dengan menerapkan jaringan cerdas di sepanjang rantai dan proses produksi untuk mengendalikan satu sama lain secara mandiri. ${ }^{2}$

Jika kita berbicara tentang digitalisasi kehidupan, maka masyarakat Indonesia merupakan negara dengan penggunaaninternet terbesar di dunia yaitu hinga mencapai 51,0\%. Sehinggauntuk menjadi seorang entrepreneur yang go digital bagi Indonesia sangat potensial sekali. Dengan jumlah akumulasientrepreneuryang ada di Indonesia masih sangat tertiggal, sebenarnya dengan technology digital seperti saat ini memungkinkan sekali untuk membuat entrepreneur berbasis online.

Bisnis online marak dan banyak dilakukan masyarakat dari segala lapisan baik pelaku bisnis yang telah profesional maupun bagi mereka yang memiliki waktu luang seperti ibu rumah tangga, karyawan, mahasiswa dan pelajar sebagai pekerjaan sampingan. Bagi pelaku business yang telah professional, mereka menjadikan bisnis online sebagai pekerjaan utama. Bisnis tersebut mereka jalankan secara full time.

Bisnis online adalah salah satu wadah yang dapat mempermudah para entrepreneur mengenai biaya berdiri serta lokasi berdirinya usaha, dengan menerapkan bisnis online seorang entrepreneur tentunya dapat menghemat pengeluaran dana, bisnis seperti ini yang sedang menjadi favorit para pelajar masa kini yaitu dengan membuka sebuah online shop. Membuka sebuah online shop merupakan sebuah permulaan yang bagus untuk menjadi seorang entrepreneur. Meski beberapa orang haya menjadi reseller atau pihak ke3, tetapi dengan starting membuka busisness seperti inilah mereka bisa belajar mandiri.

Banyak sekali orang yang sukses mengembangkan bisnis online yang sangat luar biasa seperti Nadiem Makarim manajer CEO PT. Gojek Indonesia yang berawal saat ia melihat permasalahan utama pengendara ojek yang menghabiskan

${ }^{2}$ Lee, J., Lapira, E., Bagheri, B., Kao, H., (2013). Recent Advances and Trends in Predictive Manufacturing Systems in Big Data Environment. Manuf. Lett. 1, 38-41. 
banyak waktu untuk menunggu pelanggan, ada pula Tirta Mandira Hudhi, pendiri Shoes and Care yang berawal dari hobi membersihkan sepatu, ada lagi yang lainnya seperti Iman Usman dan Adamas Syah Belva Devara sebagai CEO dan CO Founder Ruang Guru, dan masih banyak lagi. Selain ada juga pelajar yang berentrepreneur, contohnya Byainilislach, Ayu Kampez, dan Bobo Taichan, Swiwings.

Ketika seseorang membuka bisnis online seperti ini, maka secara tidak langsung ia akan belajar untuk merencanakan bagaimana agar bisnis online mereka mampu digandrungi di masyarakat maupun belajar untuk menghitung laba/rugi yang mereka terima. Oleh karena itu, sekolahmenengah kejuruan (SMK) seharusnya memberikan layanan pendidikan dengan berbagai metoda untuk mengembangkan kualitaspelajar: higher order mental skills, punya mentalitas yang mapan dalam berwirausaha di era revolusi industri 4.0.Lalu bagaimana pembelajaran yang pas untuk diterapakan di era revlousi industry kali ini sehingg mampu mengembangkan potensi-potensi entrepreneurship siswanya.

Fenomena di atas harus diantisipasi secara fair oleh lembaga penddikan yang konsen dalam bidang profesi dan kerja.Pertanyannya, sudahkah peserta didik kita dibekali dengan berbagai kompetensiuntuk masuk dunia kerja era Revolusi Industri (RI) ke 4.0? Padahal Fase revolusi teknologi mengubah cara beraktifitas manusia dalam skala ruang lingkupyang kompleks, dan transformasi dari pengalaman hidup sebelumnya. Manusia bahkan akan hidup dalam ketidak pastian global,Permasalahan pengangguran dan daya saing sumber daya manusia menjadi tantangan yang nyata bagi Indonesia. Ini adalah tantangan yang dihadapi Indonesia juga ditambah oleh tuntutan perusahaan dan industry, sehingga perlu membekali anak didik kita dengan bekal entrepreneurship yang mapan sehingga bias menghadapi era RI 4.0 dengan baik. Indonesia juga diprediksi akan mengalami bonus demografi pada tahun 2030-2040, yaitu penduduk dengan usia produktif lebih banyak dibandingkan dengan penduduk non produktif. Jumlah penduduk usia produktif diperkirakan mencapai 64 persen dari total penduduk Indonesia yang diperkirakan mencapai 297 juta jiwa. Oleh sebab itu, banyaknya penduduk dengan usia produktif harus diikuti oleh peningkatan kualitas, baik dari sisi pendidikan, keterampilan, dan kemampuan dalam berwirausaha.Dalam rangka 
menghadapi terjadinya bonus demografi kami sangat sekali tertarik untuk mengadakan riset secara mendalam dengan thema “Implementasi Pembelajaran Bisnis Online Berbasis Android Dalam Mengembangkan Sense Entrepreneurship Siswa Menghadapi revolusi industri 4.0"

\section{Pembelajaran business online}

Prof. Dr. Ali Ghufron Mukti, MSc. Ph.D sebagai Direktur Jenderal Sumber Daya Ilmu Pengetahuan, Teknologi, dan Pendidikan Tinggi, menjelaskan bahwa pembelajaran di era Revolusi Industri 4.0 dikelompokkan menjadi tiga model yaitu: model konvensional face-to-face; model daring dan otomatisasi; serta model blended learning (2018). Untuk membantu mengatasi masalah pembelajaran Inovasi Pembelajaran Kearsipan Digital di Era Revolusi Industri 4.0. Kearsipan pada era digital sekarang ini, maka model pembelajaran yang tepat untuk diterapkan adalah model blended learning. Model blended learning memadukan pembelajaran online berbasis web (e-learning) dan pembelajaran face-to-face di kelas atau di laboratorium. Lalima and Dangwal (2017) menyebut blended learning sebagai upaya inovatif yang menggabungkan kelebihan dari pembelajaran di kelas (offline) dan online.

Al-Nuaimy (2001) mengidentifikasi beberapa kelebihan pembelajaran online, yaitu: browsers yangmerupakansoftware internet dapat digunakan secara bebas, memiliki kemampuan multi-platform, dapat memperbaharui isi dan struktur secara mudah dan cepat, bergeser dari biaya pemrograman menjadi biaya desain struktur dan isi, tidak banyak membutuhkan dukungan teknis, dapat mengontrol akses lebih cepat dalam menyelesaikan produk, , serta dapat digunakan untuk pembelajaran jarak jauh. ${ }^{3}$

Jika strategi pembelajaran yang digunakan mendukung komponen pembelajaran maka pembelajaran berbasis web dapat memberikan dampak positif kepada peserta didiksesuai dengan learning outcomes, memfasilitasi collaborative learning danself-directed, serta menyediakan kegiatan praktik dan umpan balik. Keterampilan kognitif, psikomotor, dan interpersonal dapat berkembang melalui e-learning. Pembelajaran berbasis web terbukti memiliki fleksibilitas yang tinggi

\footnotetext{
${ }^{3}$ Al-Nuaimy, W., Zhang, J., \& Noble, A. (2001). Web-based learning environmentfor a
} communications module. Web-Based Learning Of Communications, 114-121. 
dan sesuai dengan era Revolusi Industri 4.0. Mengadapai Revolusi Industri 4.0 sudah saatnya dikembangkan pembelajaran berbasis web oleh lembaga-lembaga pendidikan karena telah tersedia sarana teknologi internet di sekolah-sekolah.

Howrey memberikan saran agar pengajar yang akan menggunakan e-learning sebaiknya diimplementasikan secara blended learning. E-learning akan lebih efektif apabila diterapkan sebagai web-supported instruction, tanpa menghilangkan pembelajaran di kelas. Web-supported instruction lebih menekankan pemanfaatan web sebagai pendukung pembelaran untuk menyampaikan tugas-tugas yang harus dikerjakan oleh peserta didik secara mandiri. Implementasi pembelajaran berbasis web perlu diintegrasikan dengan pemilihan strategi pembelajaran yang tepat. Pembelajaran kearsipan digital lebih banyak menuntut keterampilan praktik. Oleh karena itu, strategi pembelajaran yang digunakan harus berorientasi pada kegiatan pengalaman praktik yang dilakukan oleh peserta didik. Salah satu strategi yang mengedepankan pengalaman praktik dalam pembelajaran adalah experiential learning. ${ }^{4}$

Strategi experiential learning diimplementasikan melalui 4 tahapan, satu pemberian pengalaman kongkrit, dua observasi reflektif, tiga konseptualisasi abstrak, dan empat eksperimen aktif. Melalui empat tahapan learning tersebut peserta didik dapat memiliki pengalaman dan keterampilan nyata serta dapat mengkonstruksikan pengetahuannnya berdasarkan exprience tersebut.

Mengutip beberapa pernyataan filosof yang menggambarkan pentingnya exprience/pengalaman dalam proces pembelajaran. John Dewey menyatakan bahwa ada hubungan yang sangat erat dan penting antara proses pengalaman nyata dan pendidikan. Senada dengan Benjamin Franklin yang mernyatakan "beritahu saya dan saya lupa, ajari saya dan saya ingat, libatkan saya dan saya belajar". Sedangkan Albert Einstein menyatakan bahwa satu-satunya sumber pengetahuan (the sources of knowlegde) adalah pengalaman. Kalimat-kalimat para filosof dan ilmuwan di atas menunjukkan bahwa pengalaman sangat penting untuk membangun pengetahuan seseorang.

\footnotetext{
${ }^{4}$ Howrey, J. and Quinn, K. (2016). Assessing Student Attitudes to Moodle versusPrint Materials for L2 Vocabulary Acquisition. International Journal ofInformation and Education Technology, Vol.6,No. 1.
} 
Kegiatan business online merupakan bagian dari masyarakat milenial yang hidup pada era Revolusi industri saat ini. Manuel Castells dalam bukunya yang berjudul Information Age: Economy, Society and Culture menyebutkan akan kemunculan sebuah ekonomi, masyarakat dan budaya baru yang ditinjau dari aspek revolusi teknologi informasi, seperti komputer, internet dan lain sebaginya. ${ }^{5}$

Munculnya revolusi teknlogi informasi ini yang disebut oleh Manuel Castells sebagai masyarakat informasi, yang mana sumber primer produktivitas masyarakat dengan mengoptimalkan kombinasi penggunaan factor-factor produksi berbasis pengetahuan dan informasi. Semuanya sangat bergantung pada perkembangan technologi baru yang mampu mengembangkan logika jaringan di zaman ekonomi global yang kemudian disebut dengan ekonomi informasi. ${ }^{6}$

Menurut Hermawanher Kartajaya (2008) social media adalah perpaduan sosiologi dan teknologi yang mengubah monolog (one to much) menjadi dialogue (many to many) dan demokrasi informasi yang mengubah orang-orang dari pembaca konten menjadi publisher konten. Social media telah menjadi sangat popular karena memberikan kesempatan orang-orang untuk terhubung di dunia online dalam bentuk hubungan individu, politik dan kegiatan business.

\section{Belanja Online}

Belanja online bagian dari e-commerce yang merujuk pada aktivity business dengan memanfaatkan teknologi komunikasi seperti internet sebagai medianya, $e$ Commerce dapat diartikan sebagai segala bentuk transaksi perniagaan atau jasa (trade of goods and services) dengan menggunakan media electronik. Didalam $E$ Commerce itu terdapat perdagangan via internet seperti dalam bussiness to consumer (B2C) dan bussines to bussines (B2B) dan perdagangan dengan pertukaran (exchange) data terstruktur secara elektronik. ${ }^{7}$

Menurut McLeod \& Schell, e-commerce atau yang sering dikenal dengan online shopping atau belanja online adalah pengunaan komputer dan internet

\footnotetext{
${ }^{5}$ Sugihartati, Rahma dan Mutia, Fitri. 2010. Masyarakat \& Perpustakaan di EraRevolusi Informasi. Surabaya : Departemen Informasi Dan PerpustakaanUniversitas Airlangga.

${ }^{6}$ Sugihartati, Rahma dan Mutia, Fitri. 2010. Masyarakat \& Perpustakaan di EraRevolusi Informasi. Surabaya : Departemen Informasi Dan PerpustakaanUniversitas Airlangga.

${ }^{7}$ Grant, A. E., \& Meadows, J. H. (2008). Communication Technology Update and Fundamentals (11th Editi). Taylor \& Francis.
} 
dengan Web Browser untuk membeli dan menjual produk. Belanja online telah menjadi bagian dari manusia modern. ${ }^{8}$

Business Online atau online shopping atau via internet adalah suatu proses pembelian barang atau jasa dari mereka yang menjual melalui internet. Sejak kehadiran internet, para pedagang telah berusaha membuat toko online dan menjual produk kepada mereka yang sering menjelajahi dunia maya (internet). Para pelanggan dapat mengunjungi toko online (online store) dengan mudah dan nyaman, mereka dapat melakukan transaksi di rumah, sambil duduk di kursi mereka yang nyaman di depan computer. ${ }^{9}$

Menurut (Made, 2010) Business online adalah juga sama seperti kegiatan business yang kita kenal sehari-hari, bedanya dalam business online ini adalah segala kegiatan business dilakukan secara online dengan menggunakan media internet. ${ }^{10}$

Business online pertama kali dilakukan di Inggris pada tahun 1979 oleh Michael Aldrich dari Redifon Computers. Ia menyambungkan TV berwarna dengan komputer yang mampu memproses transaksi secara real time via kabel telepon. Sejak tahun 1980, ia menjual system business online yang ia temukan di berbagai penjuru Inggris. Tahun 1980 Pada tahun 1980, business online secara luas digunakan di Inggris dan beberapa negara di daratan Eropa seperti Perancis yang menggunakan fitur business online untuk memasarkan Peugeot, Nissan, dan General Motors. Pada tahun 1996, eBay situs business online lahir dan kemudian berkembang menjadi salah satu situs transaksi daring terbesar hingga saat ini. ${ }^{11}$

Bila saat ini teman-teman memiliki sesuatu yang dapat dibusinesskan dalam kehidupan sehari-hari, maka kemungkinan besar teman-teman dapat juga membuka business tersebut di dunia maya. Misalnya teman-teman memiliki usaha sablon kaos dan selama ini kaos tersebut dipajang di outlet teman-teman di pinggir jalan, maka kemungkinan besar teman-teman dapat mengembangkan

\footnotetext{
${ }^{8}$ McLeod, R., \& Schell, G. P. (2007). Management Information Systems. University of Virginia: Pearson/Prentice Hall.

9 Juju., Dominikus., \& Sulianta, Feri. (2010). Branding Promotion with Social Network. Jakarta:Elex Media Komputindo

10 Made, L. (2010). Extreme Facebook Marketing for Giant Profits. Jakarta: Elex MediaKomputindo.

11 Aldrich, M. (2011). Online Shopping in the 1980s. International Business \& Economics Research Journal, 33(4), 57-61.
} 
usaha tersebut dengan membuka toko kaos sablon di dunia maya. Bila demikian, maka teman sudah menjalankan yang namanya "business online". Pada dasarnya pelanggan mereka dapat membeli barang apa saja dari toko online. Berbagai produk tersedia, mulai dari buku, pakaian, alat rumah tangga, mainan, perkakas, software dan bahkan asuransi. Itu pun hanya merupakan sebagian kecil dari ribuan produk yang dapat dibeli oleh pelanggan melalui internet.

\section{Perkembangan business online di Indonesia}

Business online di Indonesia semakin hari semakin menunjukkan peningkatan yang signifikan. Business online, tidak hanya dimonopoli oleh belanja barang, namun juga layanan jasa seperti perbankan yang memperkenalkan teknik ebanking. Melalui teknik e-bankin pelanggan dapat melakukan kegiatan seperti transfer uang, membayar tagihan, Internet, pembelian pulsa, listrik, air, telepon, pembayaran uang kuliah dan lain sebagainya. Business online di Indonesia mengalami perkembangan yang cukup pesat. Mulai dari situs yang menjual HP Android, gitar, butik, toko buku, makanan, bahkan hingga ke alat elektronik pun mulai dirambah oleh layanan business online.

\section{Faktor lain yang memengaruhi perilaku pembelian online}

Faktor lain yang memengaruhi perilaku pembelian online adalah persepsi risiko (risk perception). Menurut Derwall, \& Hann menytakan bahwa risiko merupakan ketidakpastian dan konsekuensi yang berhubungan dengan tindakan tindakan pelanggan. ${ }^{12}$

Kaitannya dengan pembelian, menurut Oglethorpe \& Monroe (1994) persepsi risiko merupakan persepsi pelanggan mengenai ketidakpastian dan konsekuensi-konsekuensi negatif yang mungkin diterima atas pembelian suatu produk atau jasa. Persepsi risiko pelanggan akan meningkat melalui ketidakpastian dan atau besarnya hubungan konsekuensi yang negatif. ${ }^{13}$

${ }^{12}$ Bauer, R., Derwall, J., \& Hann, D. (2009). Employee relations and credit risk. In ECCE, Maastricht University (pp. 1-43). Maastricht. https://doi.org/10.2139/ssrn.1483112

${ }^{13}$ Oglethorpe, J. E., \& Monroe, K. B. (1994). Determinants of Perceived Health and Safety Risks of Selected Hazardous Products and Activities. The Journal of Consumer Affairs, 28 (2), 326346. 
Perilaku pembelian online saat ini menurut Forsythe et al., (2006) terdiri atas tiga hal, yaitu: ${ }^{14}$

1. Visiting (search) : Calon customer pertama-tama mengakses situs e-commerce. Kunjungannya ini dilakukan setelah mengidentifikasi kebutuhan yang ingin dibeli. Namun, ada pula yang hanya sekedar ingin meluangkan waktunya melihat-lihat produk, jasa atau promo yang ditawarkan pihak e-commerce.

2. Multi-channel shopping : merupakan fitur yang disediakan oleh situs $e$ commerce dalam bentuk penyediaan berbagai macam jalur atau cara pembelian bagi pelanggannya. Hal ini bertujuan untuk memaksimalkan nilai belanja pelanggan. Pelanggan yang akan membeli bisa membeli produk dengan cara yang disenanginya. Sebagai contoh yaitu pada e-commerce Salestock. Pelanggan Salestock bisa melakukan pembelian tidak hanya melalui website, tapi bisa juga melalui aplikasi di Smartphone, Whatsapp, Line, Chat Facebook dan Instagram.

3. Purchasing : Setelah seseorang melakukan kunjungan atau pencarian dan menemukan produk atau jasa yang cocok baginya, ia kemudian akan melakukan pembelian. Ada beberapa hal yang melatarbelakangi pembelian seseorang di situs e-commerce. Pertama, seseorang melakukan pembelian karena memang membutuhkan barang atau jasa tersebut. Kedua, seseorang melakukan pembelian karena tertarik dengan promo yang ditawarkan penyedia layanan e-commerce.

\section{Pengertian Kewirausahaan (entrepreneurship)}

Kewirausahaan merupakan kemampuan merangkai dan memberdayakan semua yang dimiliki menganggap sebagai proses penciptaan sesuatu yang baru pada nilai, menggunakanwaktu dan upaya yang diperlukan, menanggung resiko keuangan, fisik, serta resiko social, menerima imbalan moneter yang dihasilkan, kepuasan dan kebebasan pribadi. Definisi wirausahawan menurut Mas ${ }^{\text {ee }}$ d dan Mahmud [8] adalah orang yang bertanggung jawab dalam menyusun, mengelola

14 Forsythe, S., Liu, C., Shannon, D., \& Gardner, L. C. (2006). Development of A Scale to Measure The Perceived Benefits and Risks of Online Shopping. Journal of Interactive Marketing, 20(2), 55-75. https://doi.org/10.1002/dir 
dan mengukur risiko business, memiliki sifat kreatif dan inovatif, selalu mengembangkan diri dengan penemuan baru. ${ }^{15}$

Pembelajaran kewirausahaan memberikan ketrampilan khusus pada anak didik, sehingga dapat mengelola ketrampilannya sebagai sumber penghidupannya. Di sini peranan pembelajaran kewirausahaan dalam implementasi ketrampilan, sehingga anak didik mampu bertahan dengan kemampuan mengelola ketrampilan dirinya.

\section{Faktor-faktor pemicu wirausaha}

Zimmerer dan Scarborough (2009)mengemukakan faktor pemicu menjadiwirausahawan antara lain: pendidikankewirausahaan, ekonomi dankependudukan,ekonomi jasa, kemajuan teknologi, gayahidup, dan peluang internasional. Faktorpendukung menjadi wirausahawan menurutHendro [3] yakni: faktor individual, suasana kerja, tingkat pendidikan,personality, prestasi pendidikan, dorongan keluarga, lingkungan dan pergaulan, selfesteem, dan keterpaksaan atau keadaan.

a. Kreativitas

Wirausahawan adalah orang kreatif dan inovatif yang selalu mengembangkan diri untuk penemuan baru. Orang-orang berbakat akan mampu menjadiwirausahawan sukses karena memilikiskill yang dibutuhkan untuk aktivitasyang "kreatif". Plotkin menyebutkanbahwa wirausahawan yang berhasiladalah yang memiliki sifat kreatif daningin tahu. Manimala berpendapatada hubungan erat antara kreatifitas dankewirausahaan. Kewirausahaan tidakakan sukses tanpa kreatifitas, dankreatifitas membutuhkan implementasinyata dalam pengembangannya. ${ }^{16}$

b. Menyempitnya kesempatan kerja

Tingkat pengangguran terbuka cenderungmeningkat dari keadaan sebelum krisis.Kesempatan kerja yang makin sempit bias dijadikan faktor pemicu untuk memilihwirausaha sebagai peluang kerja.

\footnotetext{
${ }^{15}$ Mas' ud Machfoedz dan Mahfud Machfoedz. 2004. Kewirausahaan, Suatu Pendekatan Kontemporer. UPP AMP YKPN, Yogyakarta

${ }^{16}$ Liang, T. P., \& Lai, H. J. (2002). Effect of store design on consumer purchases: An empirical study of on-line bookstores. Information and Management, 39(6), 431-444. https://doi.org/10.1016/S0378-7206(01)00129-X
} 
c. Pendidikan Kewirausahaan

Terdapat lebih dari 1.400 PerguruanTinggi Amerika Serikat menawarkanberbagai kursus dan magang dalamkewirausahaan. Mereka memiliki pusatkewirausahaan, konsentrasi gelar dalamkewirausahaan dan penawaran kurikulumbaru dalam bidang e-commerce.

d. Gaya hidup

Salah satu pemicumenjadi adalah gaya hidup. Orang dengangaya hidup mandiri dan suka kebebasancenderung menyukai usaha sendiri. 


\section{Daftar Pustaka}

Aldrich, M. 2011. Online Shopping in the 1980s. International Business \& Economics Research Journal, 33(4), 57-61.

Al-Nuaimy, W., Zhang, J., \& Noble, A. 2001. Web-based learning environmentfor a communications module. Web-Based Learning of Communications, 114-121.

Bauer, R., Derwall, J., \& Hann, D. 2009. Employee relations and credit risk. In ECCE, Maastricht University (pp. 1-43). Maastricht. https://doi.org/10.2139/ssrn.1483112

Forsythe, S., Liu, C., Shannon, D., \& Gardner, L. C. 2006. Development of A Scale to Measure The Perceived Benefits and Risks of Online Shopping. Journal of Interactive Marketing, 20(2), 55-75. https://doi.org/10.1002/dir

Grant, A. E., \& Meadows, J. H. 2008. Communication Technology Update and Fundamentals (11th Editi). Taylor \& Francis.

Howrey, J. and Quinn, K. 2016. Assessing Student Attitudes to Moodle versusPrint Materials for L2 Vocabulary Acquisition. International Journal ofInformation and Education Technology, Vol.6,No. 1 .

Irianto, D. 2017. Industry 4.0; The Challenges of Tomorrow. Disampaikan pada Seminar Nasional Teknik Industri, Batu-Malang.

Juju., Dominikus., \& Sulianta, Feri. 2010. Branding Promotion with Social Network. Jakarta:Elex Media Komputindo

Liang, T. P., \& Lai, H. J. 2002. Effect of store design on consumer purchases: An empirical study of on-line bookstores. Information and Management, 39(6), 431-444. https://doi.org/10.1016/S0378-7206(01)00129-X

Lee, J., Lapira, E., Bagheri, B., Kao, H., 2013. Recent Advances and Trends in Predictive Manufacturing Systems in Big Data Environment. Manuf. Lett. 1, $38-41$.

Made, L. (2010). Extreme Facebook Marketing for Giant Profits. Jakarta: Elex MediaKomputindo.

Mas' ud Machfoedz dan Mahfud Machfoedz. 2004. Kewirausahaan, Suatu Pendekatan Kontemporer. UPP AMP YKPN, Yogyakarta 
McLeod, R., \& Schell, G. P. (2007). Management Information Systems. University of Virginia: Pearson/Prentice Hall.

Oglethorpe, J. E., \& Monroe, K. B. (1994). Determinants of Perceived Health and Safety Risks of Selected Hazardous Products and Activities. The Journal of Consumer Affairs, 28 (2), 326-346.

Sugihartati, Rahma dan Mutia, Fitri. 2010. Masyarakat \& Perpustakaan di EraRevolusi Informasi. Surabaya: Departemen Informasi Dan Perpustakaan Universitas Airlangga. 